\title{
Dix-Hallpike Maneuver Triggered Pulsatile Occipital Headache with Geotropic Nystagmus in a Case of Type I Chiari Malformation
}

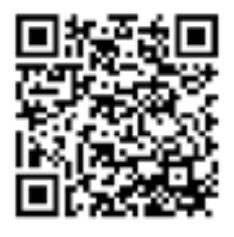

\author{
Shaabani Moslem ${ }^{1,2 *}$, Iranfar Shima ${ }^{2}$ \\ ${ }^{1}$ Audiology department, University of Social Welfare and Rehabilitation Sciences, Iran \\ ${ }^{2}$ MSc in Audiology, Audiology ward, Rofeideh rehabilitation hospital, Tehran, Iran
}

Submission: December 03, 2019; Published: December 10, 2019

*Corresponding author: Shaabani Moslem, PhD in Audiology, Assistant Professor, Audiology department, University of Social Welfare and Rehabilitation Sciences, Tehran, Iran \& Iranfar Shima, MSc in Audiology, Audiology ward, Rofeideh rehabilitation hospital, Tehran, Iran

\begin{abstract}
Here, we report a case of type I Chiari malformation (CMI), which has recently emerged at the age of 53 years and review the results of auditory-vestibular tests and brain MRI-CSF flowmetry study. Among the tests, we have more emphasized on the Dix-Hallpike maneuver, which is valuable for differential diagnosis in patients with positional vertigo and nystagmus. As the main purpose, we have underscored the need to use auditory-vestibular test-battery to assist in differential diagnosis and appropriate referral of patients with atypical positional dizziness and/ or nystagmus in Dix-Hallpike maneuver.
\end{abstract}

Keywords: DHM: Dix-Hallpike maneuver; Dix-Hallpike; Chiari Malformation; Pulsatile Headache; Geotropic Nystagmus; Tonsillar Herniation; Video Head Impulse Test; Patulous Eustachian Tube

Abbreviations: BPPV: Benign paroxysmal positional vertigo; CMI: Chiari malformation type I; AAO-HNSF: American academy of otolaryngologyHead and neck surgery foundation; VHIT: Video head impulse test; MRI: magnetic resonance imaging; CSF: cerebrospinal fluid; daPa: decapascal; MEP: middle ear pressure; ETFT: eustachian tube function test; VOR: vestibulo-ocular reflex; SNHL: sensorineural hearing loss; pET: patulous eustachian tube; CPN: central positional nystagmus

\section{Introduction}

The Dix-Hallpike maneuver (DHM) is the gold standard test for benign paroxysmal positional vertigo (BPPV) diagnosis. BPPV considered as the most common type of vertigo. BPPV can involve any of three semicircular canals but the posterior canal-BPPV (PC-BPPV) is the most frequent variant [1-2]. The BPPV usually occurs between the ages of 40-60 years [2]. DHM is known as the definitive test for diagnosis of PC-BPPV [2-3]. Given the prevalence of BPPV, and the known risks of undiagnosed and untreated BPPV [4], it is reasonable to perform DHM for all patients, especially in the above age range, who complain of positional dizziness. However, there are several contraindications for performing DHM including, but not limited to, cervical spine pathologies, rheumatoid arthritis, Arnold-Chiari malformation (cerebellar ectopia), and carotid sinus hypersensitivity [5]. Of these, Chiari malformation type I (CMI), is our focus in the present article. CMI, the most common type of Chiari malformation, involves tonsillar herniation into the spinal canal greater than 3-5 mm below the basion-opisthion line (McRae's line) [6].
Studies have shown that the symptoms of CMI develop during neck extension [7], like Dix-Hallpike position, so made it a contraindication for CMI. However, in the following case report, we describe a patient with undiagnosed CMI, who referred to us for evaluation of autophony and positional dizziness, in which the DHM along with other auditory-vestibular tests resulted in proper referral for neuroimaging and definite diagnosis of CMI in the patient. Overall, the main purpose of this article is to put further emphasis on identifying atypical signs in DHM that may indicate central disorders. In the present case, DHM to the left side led to a geotropic nystagmus associated with pulsatile headache in the left occipital region, which was an atypical finding that headed us to further research.

\section{Case Reports}

The patient was a 53-year-old woman who worked as an office clerk. A neurologist referred the patient to us for a comprehensive evaluation of the auditory and vestibular systems. We evaluated 
the patient at the audiology ward of Rofeideh rehabilitation hospital.

In response to our first question about her chief complaint, she has only complained of severe autophony in the left-ear and -palate within the last month. The autophony was so severe to the extent that she had to whisper in answering our questions. However, when we asked about the origin of the problem, the patient pointed out that her symptoms developed about 2 months ago. She added that the symptoms provoked following the last swimming experience in a public swimming pool she has dived several times from diving board. The patient's symptoms were including pulsatile occipital headache exacerbated in some head positions, neck pain that was more prominent on the left side, dysphagia, depression, and slight dizziness during position changing. The patient also noted that she had lost about $13 \mathrm{Kg}$ in the past 2 months (from 76- to 63-Kg).

During this period, the patient accustomed to taking nova fen and fluoxetine. The patient has stated to be in good health and not taking any medication before the symptoms initiated. It should be asserted that the patient's evaluation in our ward were completed within 90 minutes and because of her severe autophony, taking history completed during some rest periods given to the patient.

We performed these tests for the patient: otoscopy, tympanometry, acoustic reflex, eustachian tube function (ETF), audiometry, video head impulse test (VHIT), and videonystagmography (VNG). Considering the results of auditoryvestibular test-battery, the neurologist requested brain MRI with CSF flowmetry which results subsequently reviewed by our research team.

\section{Results}

The otoscopy of both ears was normal. Tympanometry (via MADSEN Zodiac 901 device) using 226-Hz probe tone showed "type as" in both ears (static compliance of $0.22 \mathrm{ml}$ and $0.21 \mathrm{ml}$ in the right and the left-ear, respectively). Ipsilateral acoustic reflex thresholds at frequencies of 500-4000 Hz obtained in the level of 90-95 dB HL in both ears. In ETF test (ETFT) following Valsalva maneuver, middle-ear pressure (MEP) changed from -55 to -10 daPa for the right-ear, and interestingly from -10 to 32767 da Pa for the left-ear (Figure 1).
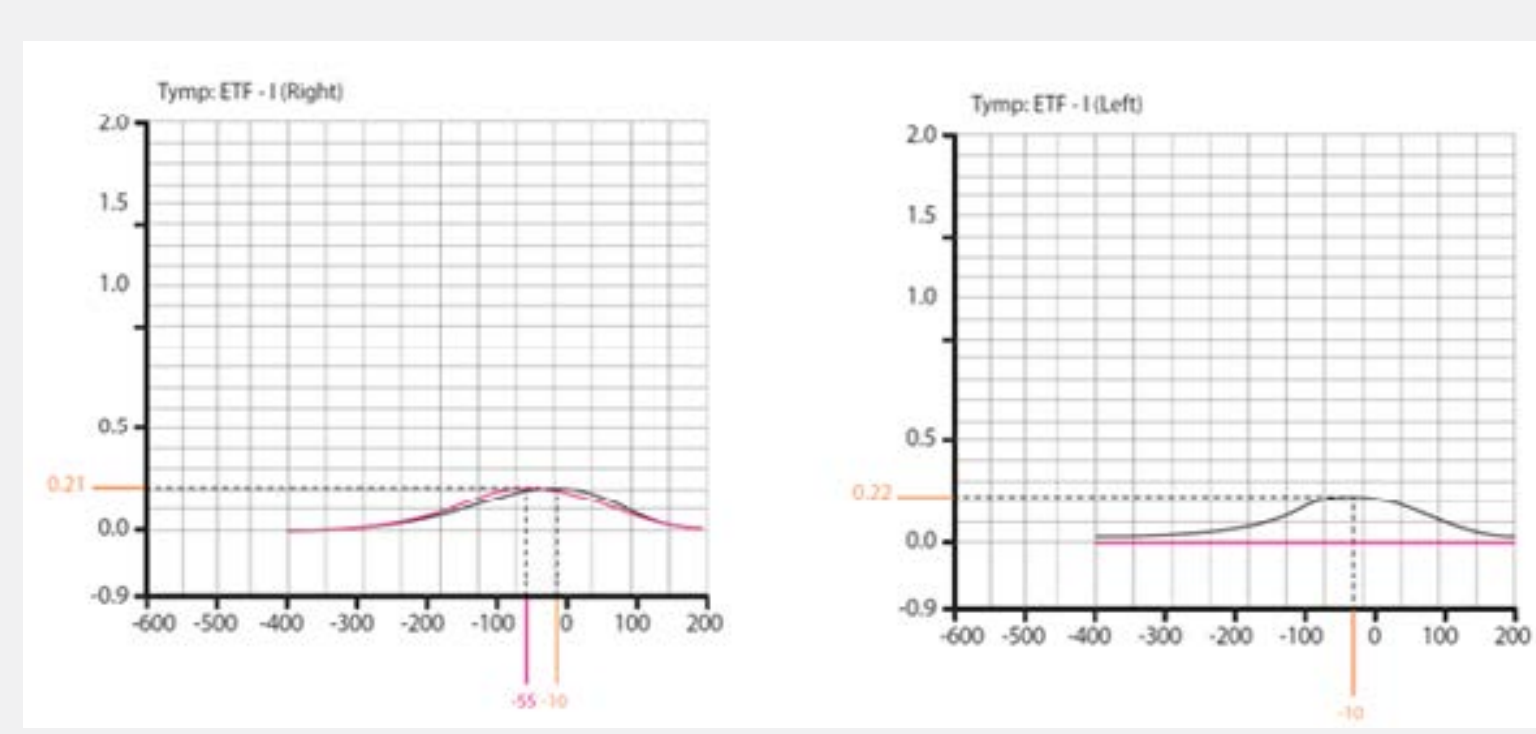

Figure 1: Eustachian tube function test (ETFT) results. Valsalva maneuver changed the middle-ear pressure (MEP) from -55 to -10 daPa in the right-ear, and from -10 to 32767 daPa in the left-ear (Figure 1). This instantly increase in MEP indicated patulous eustachian tube in the left side.

Audiometry (via MADSEN Astera device) showed a high frequency gently sloping (HFGS) audiogram in the right-ear and a high frequency steeply sloping (HFSS) audiogram in the leftear (Figure 2) [8, for more details on audiogram configurations]. Speech recognition threshold (SRT) was $15 \mathrm{~dB}$ HL in both ears. Word recognition scores (WRS) were 96 and $92 \%$ in the right- and left-ear, respectively. SRT and WRS values were consistent with audiograms. Video head impulse test (VHIT) (via SYNAPSYS VHIT Ulmer device) revealed normal vestibulo-ocular reflex (VOR) gain in all semicircular canals (SCCs) (Figure 3). We considered the normal range for VOR gain as follows: 0.8-1.2 for lateral SCCs and 0.7-1.2 for vertical SCCs [9]. In addition, we did not record any early saccades that include overt and covert saccades (Figure 3). 

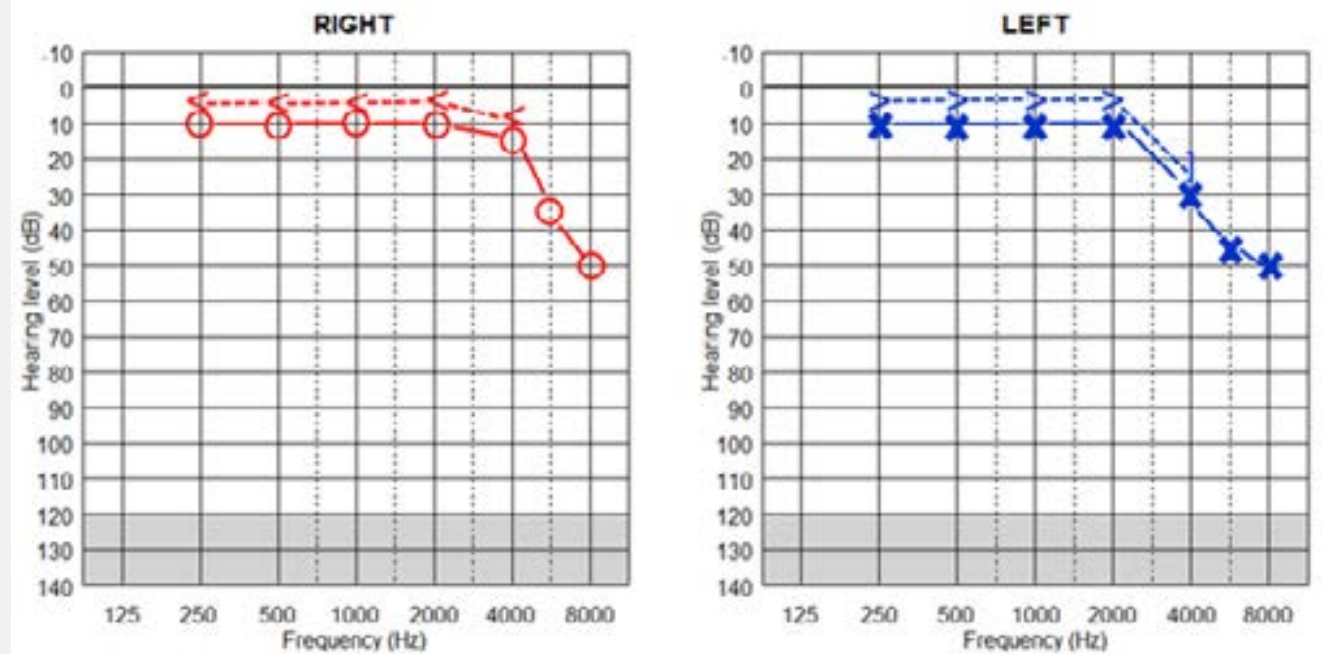

Figure 2: Audiometry results (audiograms). A high frequency gently sloping (HFGS) audiogram recorded in the right-ear. However, a high frequency steeply sloping (HFSS) audiogram recorded in the left-ear..

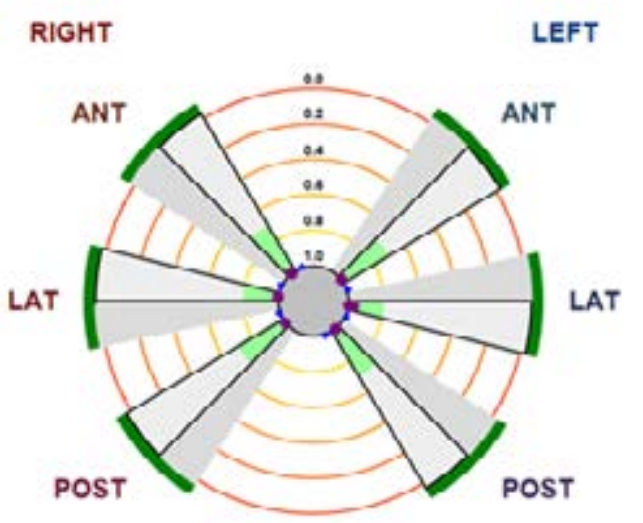

\begin{tabular}{|c|c|c|c|c|c|c|c|c|}
\hline \multicolumn{3}{|c|}{ imoulass } & \multicolumn{3}{|c|}{ VOR } & \multicolumn{3}{|c|}{ Earty soccoses } \\
\hline \multicolumn{2}{|c|}{ Cand } & $n$ & Moon & $\%$ & Asymenteby & Ratio & Mean & $\begin{array}{l}\text { Masn } \\
\text { apparenc }\end{array}$ \\
\hline \multirow{2}{*}{ Art } & R & 12 & 1.19 & 004 & \multirow{2}{*}{$0 \%$} & $0 \leqslant$ & & \\
\hline & L & 7 & 1.10 & 006 & & os & & \\
\hline \multirow{2}{*}{ Lat } & R & 8 & 1.05 & 005 & \multirow{2}{*}{ os } & Os & & \\
\hline & $L$ & 6 & 1.04 & 0.03 & & os & & \\
\hline \multirow{2}{*}{ Post } & R & 5 & t.45 & 0.04 & \multirow{2}{*}{$2 \%$} & ON & & \\
\hline & 6 & 6 & 1.24 & 004 & & O\& & & \\
\hline
\end{tabular}

Figure 3: Video head impulse test (VHIT) results. Left: The canalogram revealed normal vestibulo-ocular reflex (VOR) gain for all semicircular canals (SCCs). The concentric circles represent the limits of VOR gain. The closer the impulse registered to the center, the greater the gain. Right: This table shows the details of the test. The column of "Early saccade" shows that no corrective saccades have occurred.

Table 1: Results of horizontal and vertical saccade tests.

\begin{tabular}{|c|c|c|c|}
\hline Random horizontal saccade test & Latency (ms) & Velocity (\%/sec) & Precision (\%) \\
\hline Rightward & 290 & 319 & 101 \\
\hline Leftward & 303 & 278 & Precision (\%) \\
\hline Random vertical saccade test & Latency (ms) & 213 & 75 \\
\hline Upward & 303 & 128 & 72 \\
\hline
\end{tabular}

ms: milliseconds; \%sec: degrees/second 


\section{Global Journal of Otolaryngology}

In the oculomotor part of videonystagmography (VNG) test (via SYNAPSYS VNG Ulmer device), we did not record any gaze abnormality or gaze nystagmus in both horizontal and vertical gaze tests that included center gaze $\left(0^{\circ}\right)$ and $20^{\circ}$ deviations to the right, left, up, and down. Horizontal and vertical random saccade tests also showed normal results considering all parameters of latency, velocity, and precision (Table 1). Furthermore, horizontal and vertical optokinetic tests using $20 \%$ s checkerboard pattern stimulus showed normal and symmetric results. However, the smooth pursuit test showed abnormal morphology (i.e. completely saccade like in both directions) and very low gain (i.e. near zero) in both horizontal $(0.45 \mathrm{~Hz})$ and vertical $(0.3 \mathrm{~Hz})$ subtests (Figure 4).

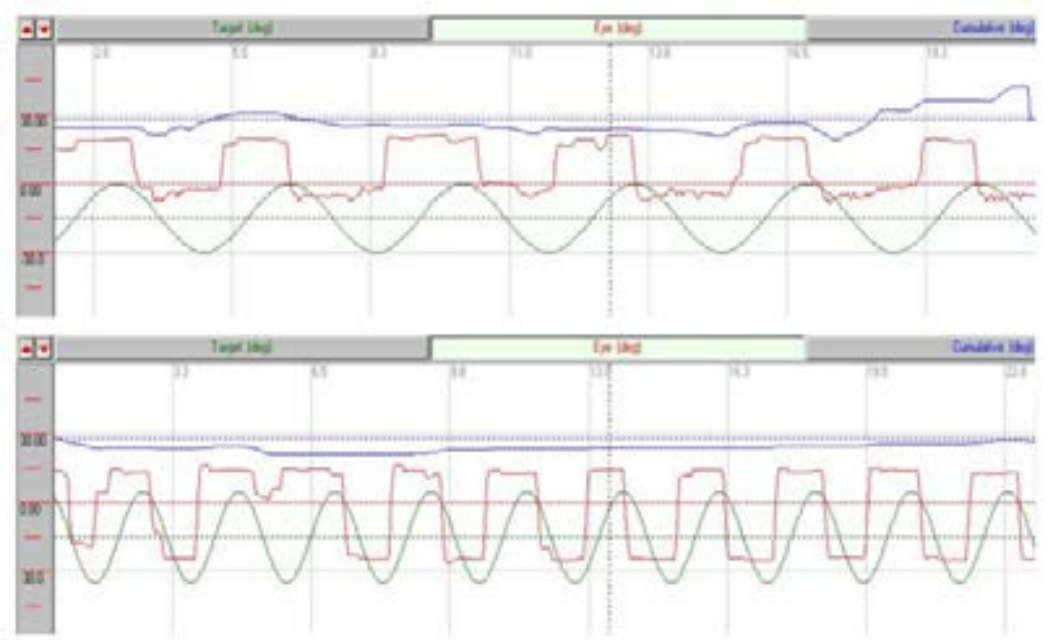

Figure 4: Smooth pursuit test results. Upper: The horizontal pursuit test depicted. The test recorded using a visual target (green and lower curve) that has moved with frequency of $0.45 \mathrm{~Hz}$. The morphology of the eye curve (red curve) is completely saccade-like. The cumulative curve (blue curve) showed symmetric response with nearly zero gains. Lower: The vertical pursuit test depicted. The test recorded using a visual target (green and lower curve) that has moved with frequency of $0.3 \mathrm{~Hz}$. The results are the same as the horizontal pursuit test.

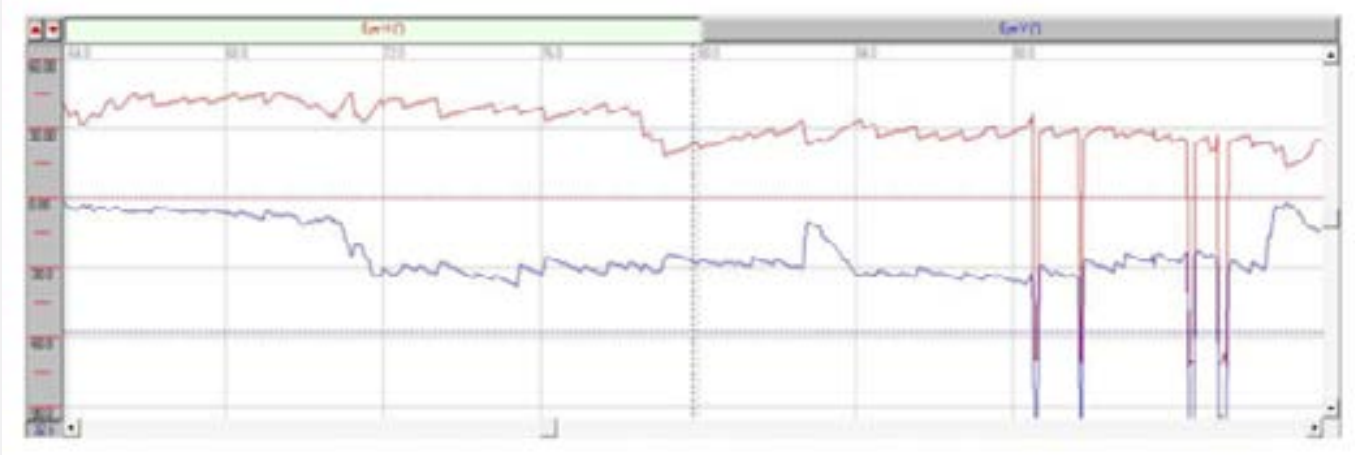

Figure 5: Dix-Hallpike maneuver (DHM) to the left side. Upper and lower traces indicated horizontal and vertical eye movements in degrees, respectively. The traces show a persistent left-up-beating nystagmus.

In the peripheral vestibular part of VNG test, we did not record any spontaneous nystagmus. Moreover, the head-shaking test revealed normal results (i.e. no head-shaking nystagmus or dizziness occurred). DHM to the right side provoked slight rightup-beating nystagmus without any dizziness. DHM to the left side provoked significant left-up-beating nystagmus with pulsatile occipital headache (Figure 5). The nystagmus sustained as the position preserved but the headache lasted only a few seconds (supplementary Video 1. DHM to the left side). The patient did not report nausea, true vertigo, or any other symptoms. Interestingly, providing visual fixation almost eliminated the nystagmus (supplementary Video 1. DHM to the left side). On the other hand, repeating DHM had the same result.

As a final peripheral test, mono-thermal caloric test using a cold air stimulus $\left(24^{\circ} \mathrm{C}\right)$ performed (via DIFRA Cool Star device). The peak of slow phase velocity was 36.9 and $44.3 \%$ in the right- and left-ear stimulation, respectively. In addition, 


\section{Global Journal of Otolaryngology}

visual fixation showed normal results. Therefore, the caloric test showed normal and symmetric results. In the conventional MRI (T2 TSE), tonsillar herniation indicated CMI was evident. The herniation depth was about $15.15 \mathrm{~mm}$ below McRae's line (Figure 6). The Figure 6 shows that the width of McRae's line is about $36.82 \mathrm{~mm}$. In the phase contrast images, CSF pulsation and CSF flow based on cardiac circulation were well visible in the foramen of Monro, aqueduct of Silvius, and subarachnoid spaces. It should be noted that there was not any detectable flow in the basal cistern (supplementary Video 2. CSF flowmetry). However, hydrocephalus or ventriculomegaly was not apparent. Also, worth mentioning that tonsillar herniation was asymmetric and more prominent in the left side of coronal sections of MRI-T2 (Figure 7).
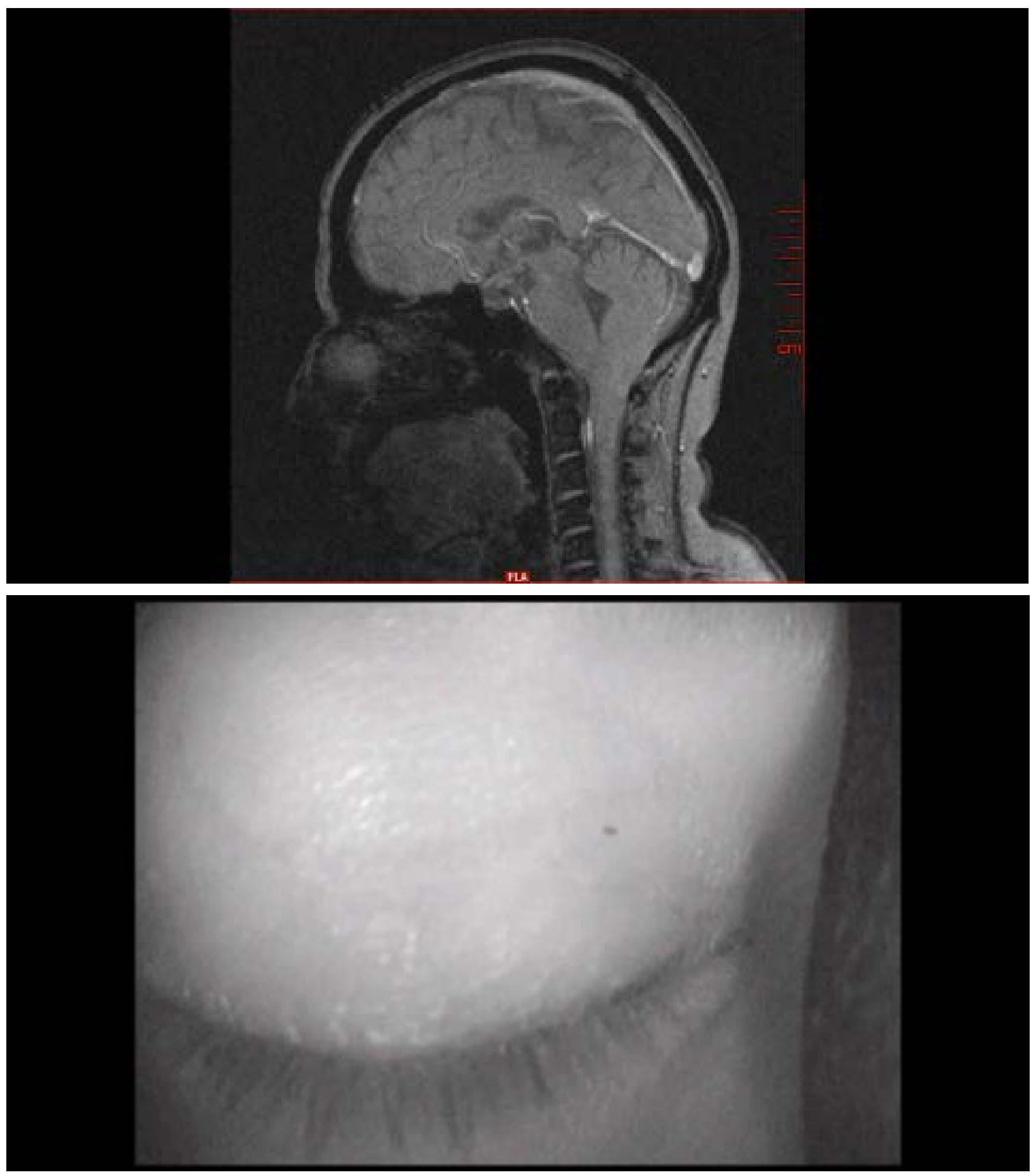


\section{Global Journal of Otolaryngology}

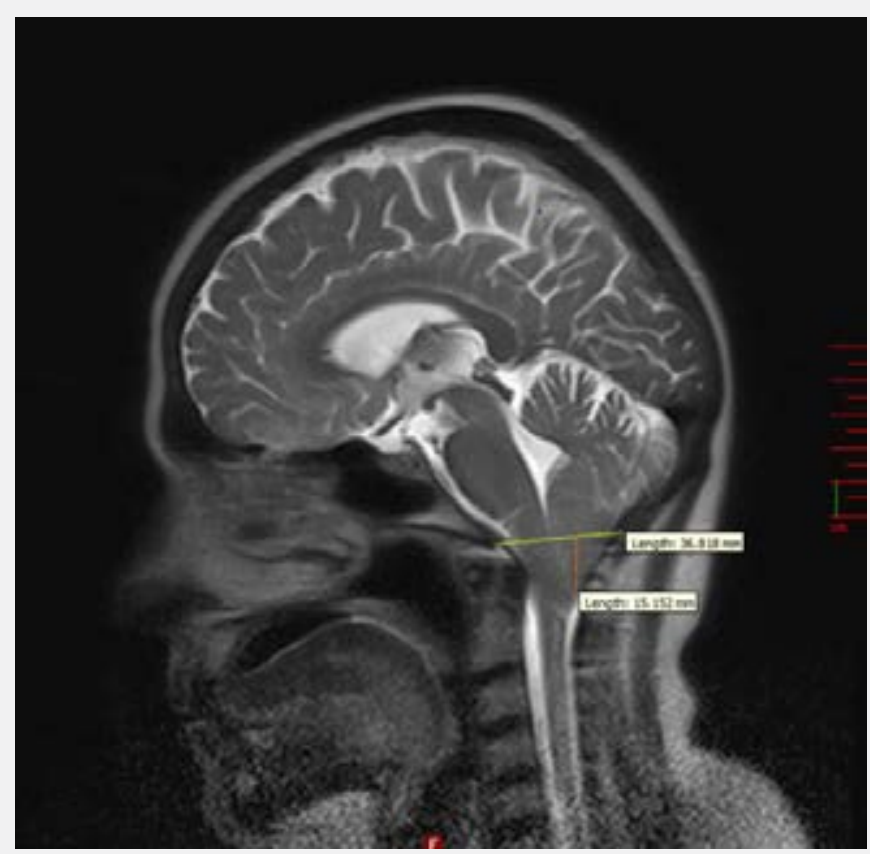

Figure 6: Sagittal T2-weighted MRI of the present patient. Note the length of the McRae's line (A) and the depth of tonsillar herniation (B).

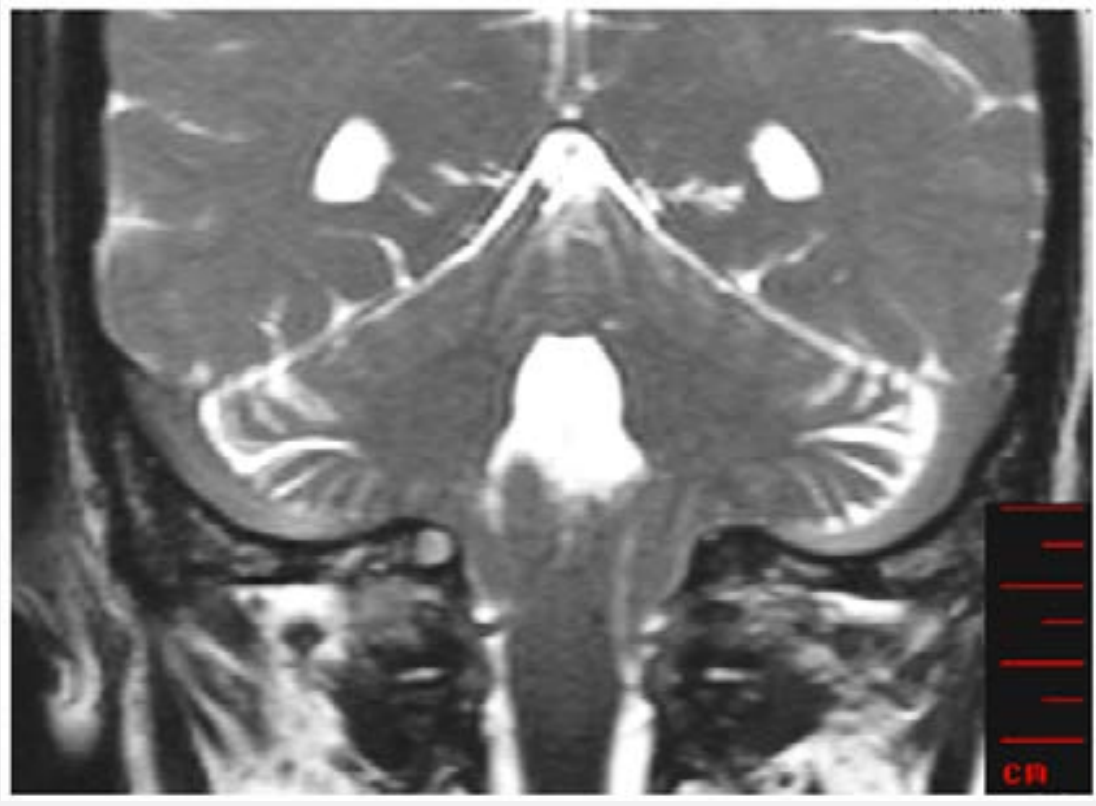

Figure 7: Coronal T2-weighted MRI of the present patient. Note that the left cerebellar tonsil displaced more inferiorly in comparison with the right cerebellar tonsil.

\section{Discussion}

In the above case report, we described a case of CMI and reviewed the results of auditory-vestibular tests and MRI-CSF flowmetry study. Here, we discuss the results from a clinical point of view. The ETFT results in the left ear showed an instantly increase in MEP which indicates patulous eustachian tube (pET) in the left side [10] and justifies the patient's autophony. It seems that, as reported in previous studies [11], the patent eustachian tube in this patient can be attributed to her severe weight loss within two months. It is also worth noting that Valsalva maneuver considers as a contraindication in CMI [7] but here in an undiagnosed patient, it helped us to diagnose the left pET. On the 
other hand, the clinician should consider whether the patient's dizziness coincides with nasal breathing. In such cases, unlike our patient, dizziness-induced pET can be considered as a major cause [12].

In most cases of CMI, like the present patient, bilateral sensorineural hearing loss (SNHL) has been reported $[13,14]$. To explain it, theories such as compressional effect of cerebellar tonsils on cochlear nuclei and/or cochlear damage due to elevated CSF pressure have been suggested, which need to be substantiated by extensive research in each patient. Undoubtedly, the impact of high frequency presbycusis should also be considered in this case [15]. Therefore, it is difficult to prove that bilateral SNHL or further high-tone loss on the left side can be justified by CMI or more tonsillar herniation on the left side. VHIT results were within normal limits. However, VOR gains for vertical canals were near the upper limit of normal range. Moreover, downward head impulses stimulated anterior SCCs have had higher gains compared to upward head impulses. Such asymmetry in vertical VOR is reported in patients with cerebellar disease [16]. Therefore, it is rational to consider this asymmetry in future research on VHIT.

Several research on CMI recorded some abnormalities in the saccade, pursuit, and gaze tests [17]. However, as reported above, we have only recorded abnormal responses in the smooth pursuit test. Studies on the ocular motor control showed that lesions of the flocculus/paraflocculus (tonsil) result in a decrease in gain of the smooth pursuit test [16]. Involvement of other oculomotor tests may arise from the exact location, and the dimensions of the lesion.

Previous studies have found that in CMI, positional vertigo and nystagmus usually occurs $[14,18]$. What matters is its differentiation from BPPV. Based on the indicators of central positional nystagmus (CPN) proposed by Macdonald [19], our case could be considered as a CPN patient not a BBPV one. These indicators include onset-latency of nystagmus following DHM (3s), duration of nystagmus (more than 1 min or if the head position maintains), absence of fatigue with repetitive positioning, direction-changing nystagmus with changing head position, and absence of rotational vertigo. Based on the current guideline proposed by ANO-HNSF, brain neuroimaging should be suggested if positional nystagmus and dizziness are not consistent with BPPV [4]. As we mentioned above, the MRI results confirmed a structural defect in the cerebellum.

One study has suggested the ranges of $36.21 \pm 2.6 \mathrm{~mm}$ and $36.82 \pm 1.91 \mathrm{~mm}$ as normal and abnormal limits, respectively, for McRae's line [20]. Therefore, considering McRae's line as a reference for characterizing the tonsillar herniation [21], our patient is exactly in the abnormal range, which indicates CMI. Moreover, clinical presentation of our patient with only left-sided pulsatile occipital headache and neck pain correlates with more ectopia on the left cerebellar tonsil (Figure 7). This correlation has also mentioned in previous studies [22].

Accordingly, the occurrence of pulsatile occipital headache in DHM can be considered as another indicator of CPN. Moreover, based on this case, and others reported in previous studies $[23,24]$, we can argue that, at least in an asymptomatic CMI patient, awkward and repeated jumping into swimming pool generates a caudally directed force on the cranial posterior fossa that resulted in such puzzling instances of symptomatic tonsillar ectopia in the sixth decade of life. Confirming this claim requires more extensive studies. This case report further supports the need to use auditory-vestibular test-battery to assist in differential diagnosis and appropriate referral of patients with atypical positional dizziness and/or nystagmus in Dix-Hallpike maneuver.

\section{Acknowledgement}

The authors appreciate the support of the Clinical Research Development Center of Rofeideh Rehabilitation Hospital, Tehran, Iran.

\section{References}

1. Noda K, Ikusaka M, Ohira Y, Takada T, et al. (2011) Predictors for benign paroxysmal positional vertigo with positive Dix-hallpike test. International journal of general medicine 4: 809.

2. You P, Instrum R, Parnes L (2018) Benign paroxysmal positional vertigo. Laryngoscope investigative otolaryngology 4(1): 116-123.

3. Furman J M, Cass S P (1999) Benign paroxysmal positional vertigo. New England Journal of Medicine 341(21): 1590-1596.

4. Bhattacharyya N, Gubbels S P, Schwartz S R, Edlow J A, El Kashlan, et al. (2017) Clinical practice guideline: benign paroxysmal positional vertigo (update). Otolaryngology-Head and Neck Surgery 156(3): S1S47.

5. Humphriss R L, Baguley D M, Sparkes V, Peerman S E, Moffat D A (2003) Contraindications to the Dix-Hallpike manoeuvre: A multidisciplinary review: Contraindicaciones de la maniobra de Dix-Hallpike: Una revisión multidisciplinaria. International journal of audiology 42(3): 166-173.

6. Lawrence B J, Urbizu A, Allen P A, Loth F, Tubbs R S, et al. (2018) Cerebellar tonsil ectopia measurement in type I Chiari malformation patients show poor inter-operator reliability. Fluids and Barriers of the CNS 15(1): 33.

7. Spencer R, Leach P (2017) Asymptomatic Chiari Type I malformation: should patients be advised against participation in contact sports? British journal of neurosurgery 31(4): 415-421.

8. Kim J M, Na M S, Jung K H, Lee SH, Han J S, et al. (2016) The Best-Matched Pure Tone Average and Speech Recognition Threshold for Different Audiometric Configurations. Korean Journal of OtorhinolaryngologyHead and Neck Surgery 59(10): 725-729.

9. Yollu U, Uluduz D U, Yilmaz M, Yener H M, Akil F, et al. (2017) Vestibular migraine screening in a migraine-diagnosed patient population, and assessment of vestibulocochlear function. Clinical Otolaryngology 42(2): 225-233. 
10. Yazeed Alshawi, Abdulmalik Ismail, Nora Almegil, Zaid almubarak (2018) The Effect of Valsalva and Toynbee Maneuvers on Tympanometry Parameters in Normal and Retracted Tympanic Membrane. Glob J Oto 14(4): 555896.

11. Pascoto G, Abreu C, Silva M L, Weber R, Pignatari S S, et al. (2014) The impact of acute loss of weight on eustachian tube function. International archives of otorhinolaryngology 18(4): 376-379.

12. Kitajima N, Sugita Kitajima A, Kitajima S (2016) A case of patulous Eustachian tube associated with dizziness induced by nasal respiration. Auris Nasus Larynx 43(6): 702-705.

13. Dolgun H, Turkoglu E, Kertmen H, Yilmaz E R, Sekerci Z (2009) Chiari Type I malformation presenting with bilateral hearing loss. Journal of Clinical Neuroscience 16(9): 1228-1230.

14. Jiménez G G, Gutiérrez Á M, De Lucas E M, San Román N V, Laez, R M, et at. (2015) Audio-vestibular signs and symptoms in Chiari malformation type i Case series and literature review. Acta Otorrinolaringologica (English Edition) 66(1): 28-35.

15. Arvin B, Prepageran N, Raman R (2013) "High Frequency Presbycusis"Is There an Earlier Onset? Indian Journal of Otolaryngology and Head \& Neck Surgery 65(3): 480-484.

16. Kheradmand A, Zee D S (2011) Cerebellum and ocular motor control Frontiers in neurology 2: 53.

17. Shaikh A G, Ghasia F F (2015) Neuro-ophthalmology of type 1 Chiari malformation. Expert review of ophthalmology 10(4): 351-357.

18. Fernández A A, Guerrero A I, Martínez M I, Vázquez M E A, Fernández $J$ B, et al. (2009) Malformations of the craniocervical junction (Chiari type I and syringomyelia: classification, diagnosis and treatment). BMC Musculoskeletal disorders 10(1): S1.

19. Macdonald N K, Kaski D, Saman Y, Al Shaikh Sulaiman A, Anwer A, et al. (2017) Central positional nystagmus: a systematic literature review. Frontiers in neurology 8: 141.

20. Alkoç O A, Songur A, Eser O, Toktas M, Gönül Y, et al. (2015) Stereological and morphometric analysis of MRI Chiari malformation type 1. Journal of Korean Neurosurgical Society 58(5): 454.

21. Rydell R E, Pulec J L (1971) Arnold-Chiari malformation: neurootologic symptoms. Archives of Otolaryngology 94(1): 8-12.

22. Tubbs R S, Wellons III J C, Oakes W J (2002) Asymmetry of tonsillar ectopia in Chiari I malformation. Pediatric neurosurgery 37(4): 199202.

23. Borius P Y, Gouader I, Bousquet P, Draper L, Roux F E (2010) Cervical spine injuries resulting from diving accidents in swimming pools: outcome of 34 patients. European spine journal 19(4): 552-557.

24. Meadows J, Kraut M, Guarnieri M, Haroun R I, Carson B S (2000) Asymptomatic Chiari Type I malformations identified on magnetic resonance imaging. Journal of neurosurgery 92(6): 920-926.

\section{Your next submission with Juniper Publishers will reach you the below assets}

- Quality Editorial service

- Swift Peer Review

- Reprints availability

- E-prints Service

- Manuscript Podcast for convenient understanding

- Global attainment for your research

- Manuscript accessibility in different formats

( Pdf, E-pub, Full Text, Audio)

- Unceasing customer service

Track the below URL for one-step submission https://juniperpublishers.com/online-submission.php 